\title{
$\boldsymbol{\nabla}$ Artikkeli
}

\section{Enemmän kuin liikuntaa}

\section{Jooga kaupallisessa mediakulttuurissa}

\begin{abstract}
Maailmalla suositusta joogasta on myös Suomessa tullut muodikas harrastus 2000-luvun vaihteesta lähtien. Modernin joogan kehitys ja leviäminen liittyvät läheisesti individualistisen henkisyyden kasvuun länsimaissa. Modernia sitoutumatonta henkisyyttä toteutetaan usein kuluttamalla erilaisia tuotteita ja palveluja. Myös joogasta on tullut osa globaalia hyvinvointikulttuuria ja markkinataloutta. Artikkelissa tarkastellaan sitä, kuinka henkisyys ja kaupallisuus kietoutuvat yhteen esityksissä modernista joogasta. Aineisto koostuu seitsemästä suomalaisesta aikakauslehdestä kerätyistä artikkeleista, joita on tarkasteltu laadullisella lähiluennalla. Analyysi osoittaa, että vaikka henkisyys ja kaupallisuus ovat kiinteästi liitoksissa, ovat silti ulkonäkö, hyvinvointi ja terveys modernin joogan tärkeimpiä myyntivaltteja. Joogaa käsittelevästä aineistosta löytyy myös kulutuskulttuuria haastavia näkemyksiä, joskin ne ovat selvästi vähemmistössä.
\end{abstract}

AVAINSANAT: jooga, henkisyys, kulutus, media

K irkon tutkimuskeskuksen selvityksen mukaan Suomessa on arviolta 100 o00 200 ooo joogan harrastajaa (Gallup Ecclesiastica 2011). Suomen kuntoliikuntaliikuntaliiton Liikuntatutkimus 2009-2010 mukaan joogan harrastajia on puolestaan 62000 ja potentiaalisia harrastajia 64000 (Suomen kuntoliikuntaliitto 2010). "Suomalaiset ovat kovia joogaamaan", uutisoi myös YLE verkkouutisissaan 23.10.2008'. Uutisessa kerrotaan, että Suomessa joogataan arvioiden mukaan enemmän kuin missään muualla maailmassa väkilukuun suhteutettuna, ja "marginaaliporukan puuhastelu on muuttunut kuntokeskustenkin massatuotteeksi". Voidaan sanoa, että media on ottanut joogan monin tavoin omakseen. Medialla on myös ollut tärkeä rooli joogan tunnetuksi tekemisessä ja muotilajiksi nousemisessa.

Joogan juuret ovat intialaisessa asketismissa (Samuel 2008). Nykyisissä globaaleissa muodoissaan joogan menetelmät ja päämäärät ovat kuitenkin loitonneet varhaisista yhteyksistään. 1800-luvulta eteenpäin länsimaisilla luonnontieteillä, liikuntakulttuurilla ja uskonnollis-filosofisilla suuntauksilla on ollut merkittävä vaikutus joogan erilaisten muotojen kehittymiseen (De Michelis 2004, Singleton 2010). Tutkimuskirjallisuudessa nykyisen joogailmiön eroa askeettisiin juuriinsa korostetaan tavallisesti nimittämällä 1800-luvulta asti kehittynyttä kansainvälistä joogaa "moderniksi joogaksi" (De Michelis 2004). 
Moderni asentojooga on modernin joogan alaluokka, jossa keskitytään ensisijaisesti joogan fyysisiin harjoituksiin, muiden osa-alueiden saadessa vähemmän huomiota (De Michelis 2004). Tyypillisiä modernin asentojoogan muotoja ovat esimerkiksi astangajooga, iyengarjooga, vinijooga, bikramjooga, sekä muut tunnetut asentoharjoitusta painottavat suuntaukset. Käsittelemme tässä artikkelissa modernia asentojoogaa, sillä juuri sitä edustavat suuntaukset ovat joogan nykyisen suosion ja mediahuomion keskipisteessä.

Tämän artikkelin tavoitteena on tutkia, miten henkisyys ja kaupallisuus kietoutuvat yhteen suomalaisen median esityksissä modernista joogasta. Tarkastelemme joogan representaatioita seitsemässä suomalaisessa aikakauslehdessä (Me Naiset, Kodin Kuvalehti, Hyvä Terveys, Cosmopolitan, Sport, Sara ja ET) ensin lyhyellä määrällisellä sisällön erittelyllä ja paneudumme sitten syvemmin henkisyyden ja kaupallisuuden esityksiin laadullisen lähiluennan avulla.

\section{Moderni asentojooga, individualistinen henkisyys ja kaupallisuus}

Modernin joogan synty ja kehitys kulkevat rinnakkain monien modernisaatioprosessiin liitettyjen yhteiskunnallisten muutoksien kanssa sekä Intiassa että länsimaissa. Samaan aikaan myös uskonnollisuuden luonne on muuttunut radikaalisti etenkin länsimaissa (esim. Kääriäinen ym. 2003; Taira 2006). Moderneissa yhteiskunnissa uskonnosta on tullut enenevässä määrin yksilöllisen valinnan asia (Taira 2006; Giordan 2007). Sitoutuminen uskonnollisiin instituutioihin ja niiden perinteisiin opetuksiin on laskenut tasaisesti 1900-luvun alusta. Samalla yksityinen ja yksilöllinen uskonnonharjoitus, uskonnollisten opetusten valikoiva soveltaminen, uudet uskonnolliset liikkeet sekä perinteisistä uskonnollisista yhteisöistä riippumaton henkisyys ovat yleistyneet, joskaan eivät samassa suhteessa perinteisen uskonnonharjoituksen suosion laskun kanssa (Kääriäinen ym. 2003). Monien tutkijoiden mukaan uskonnollisuuden muutokset liittyvät läheisesti individualismin kasvuun länsimaissa (esim. Heelas \& Woodhead 2005; Taira 2006; Sointu \& Woodhead 2008).

Uskontotieteilijät Paul Heelas ja Linda Woodhead (2005) ovat määritelleet individualistisen henkisyyden käsitettä suhteessa perinteiseen uskonnollisuuteen. Perinteinen uskonnollisuus on heidän mukaan "ulkoa määräytynyttä", mikä tarkoittaa sitoutumisen ja ulkopuolisen auktoriteetin (esim. jumala tai yhteisö) merkityksen korostamista. Individualistinen henkisyys puolestaan perustuu yksilölliselle valinnalle ja palvelee yksilön tarpeita. Ulkoisten auktoriteettien sijaan henkisyyttä määrittävät itseohjautuvuus, itsetuntemus ja itseilmaisu. Toisin kuin perinteinen uskonto, individualistinen henkisyys ei useinkaan edellytä sitoutumista mihinkään ryhmään tai oppiin vaan perustuu vapaaehtoiseen ja valikoivaan osallistumiseen. Samalla yksilöllinen ja valikoiva asenne ovat yleistyneet myös institutionaalisen uskonnollisuuden piirissä (Ketola 2001; Kääriäinen ym. 2003; Heelas \& Woodhead 2005).

Individualistista henkisyyttä toteutetaan yleensä omaksumalla valikoivasti uskomuksia ja käytäntöjä erilaisista perinteistä. Siksi henkisyyden harjoitus saakin mitä 
vaihtelevimpia ilmenemismuotoja, joita ovat esimerkiksi new agena tunnettu uskomusten ja käytäntöjen kirjava kokonaisuus, vaihtoehtolääkintä sekä monet itämaisiin uskontoihin pohjautuvat menetelmät, kuten taiji, aromaterapia ja jooga (Lau 2000). Individualistisen henkisyyden harjoittamiseen kuuluvissa, usein fyysisissä aktiviteeteissa, kuten modernissa asentojoogassa, korostetaan osallistujien henkilökohtaisia tarpeita ja tuntemuksia. Osallistujien sanotaan saavan harjoituksesta juuri sen, mitä he itse sattuvat etsimään. Näin ollen individualistisella henkisyydellä voidaan Heelasin mukaan tarkoittaa lähes mitä tahansa positiivisista tunnetiloista ja elämänlaadun paranemisesta metafyysisiin kokemuksiin ja uskomuksiin (Heelas 2008).

Viime vuosikymmeninä esimerkiksi monia aasialaisperäisiä uskontoja on länsimaissa brändätty uudelleen individualistiseksi ja kokemuksellisuutta painottavaksi henkisyydeksi (Taira 2006). Modernille asentojoogalle onkin ominaista opillinen ja rakenteellinen avonaisuus: kuka tahansa - taloudellisesti hyvinvoiva - voi soveltaa sen harjoituksia ja opillisia ulottuvuuksia omaan elämänkatsomukseensa parhaaksi katsomallaan tavalla. Myös harjoittajien käsityksissä henkisyys ja fyysinen harjoitus liittyvät toisiinsa. (Esim. Hasselle-Newcombe 2005; Nevrin 2008; Rautaniemi 2010; Langøien 2012.) Tämä on tyypillistä niin kutsutun notkean modernin uskonnollisuudelle yleisemminkin (Taira 2006). ${ }^{2}$

Yksilöllisyys, vapaaehtoisuus, valikoivuus ja palvelujen käyttäminen liittävät individualistisen henkisyyden leimallisesti osaksi myöhäiskapitalistista kulutuskulttuuria. Yhdysvaltalaisen Kimberly Laun (2000) mukaan individualistinen henkisyys kuuluu niin kutsuttuun New Age -kapitalismiin, missä henkisyydestä on tullut kauppatavaraa. Myös modernin joogan ympärillä pyörii valtava bisnes. Joogasta on tullut intialaisella mytologialla muista liikuntalajeista erottuva brändi, jonka varjolla markkinoidaan esimerkiksi harjoitukseen liittyviä varusteita, kuten joogamattoja ja -vaatteita. Lisäksi tarjolla on joogakirjoja, -tallenteita, -lehtiä, -kursseja -lomamatkoja ja -konsultaatioita. Jopa meikkejä, hajusteita, teetä tai pesuaineita brändätään joogalla.

Myös joogaharjoitusta on pyritty tuotteistamaan. Esimerkiksi BikramYoga on patentoitu, ja sen kehittäjän Bikram Choudhuryn lakimiehet valvovat merkin ja asentosarjan käyttöä ja haastavat pieniä joogayrittäjiä oikeuteen sekä maksamaan korvauksia, jos he ovat opettaneet Bikramin asentosarjaa ilman lisenssimaksua. ${ }^{3}$ (Philp 2009). Muistakin joogalajeista on muodostunut brändejä: joogaa markkinoidaan työkaluna, joka mahdollistaa fyysisten ja psykologisten muutosten kautta kuluttajien tulemisen paremmiksi ihmisiksi (Jain 2012).

Samaan aikaan monet joogan harrastajat vastustavat joogan tuotteistamista, käyttävät ilmaisia joogapalveluita ja kieltäytyvät hankkimasta joogatuotteita. Asketismiin pohjautuvaa joogan historiaa tulkitaan epäkaupallisella ideologialla: aina löytyy joogeja, joiden mielestä jooga ja raha eivät liity mitenkään toisiinsa ${ }^{4}$. Viime vuosina, etenkin pääkaupunkiseudulla, on toisaalta ammattimaisesti toimivien opettajien ja joogakoulujen määrä lisääntynyt merkittävästi. Joogan opettamisesta on tullut ammatinharjoittamista eli liiketoimintaa, halusivatpa toimijat sitä itse tai 
eivät. Myös joogan parissa toimivat yksilöt ja yhteisöt joutuvat ottamaan osaa kaupallisuuden ehdoilla toimivaan promootiokulttuuriin (Wernick 1991), jos ne haluavat toimia nyky-yhteiskunnassa.

Jeremy Carrette ja Richard King pitävät henkisyyden käsitteen psykologisoitumista tärkeimpänä yhdistävänä tekijänä henkisyyden ja kaupallisuuden välillä. Uskonnon paikantuminen yksilön subjektiiviseen kokemukseen on voimistanut uskonnon privatisoitumista, mikä puolestaan on mahdollistanut sen myöhemmän tuotteistumisen ja kaupallistumisen (Carrette \& King 2005). Suomalainen uskontotieteilijä Teemu Taira (2006) puolestaan toteaa nyky-yhteiskuntien uskonnollisen pluralismin palvelevan markkinatalouden etuja. Inklusivistinen moniarvoisuus johtaa Tairan mukaan väistämättä kapitalismille hyödyllisten ja hyödyttömien perinteiden erotteluun ja lopulta perinteiden muokkaamiseen vallitsevan järjestyksen tarpeisiin. Selkeimmin tämä on havaittavissa yritysmaailman tarpeita palvelevassa "kulutus- ja yrityshenkisyydessä" (Carrette \& King 2005; Taira 2006). Individualistisen henkisyyden palauttamista yksinomaan kulutuskulttuuriin on kuitenkin myös kyseenalaistettu väittäen, että henkisten harjoitteiden tavoitteena oleva kokonaisvaltaisempi käsitys itsestä voi pikemminkin kyseenalaistaa kulutuskulttuurin mekanismeja kuin vahvistaa niitä (Heelas 2008).

\section{Naiset, hyvinvointi ja media}

Individualistisen henkisyyden lisäksi joogan ja kulutuskulttuurin yhteyttä voidaan tarkastella myös niin kutsutun terapeuttisen eetoksen ja holistisen hyvinvoinnin näkökulmasta. Kulutushistorian tutkijoiden Richard Wightman Foxin ja Jackson Learsin mukaan 1900-luvun vaihteessa protestanttisen itsekieltäymyksen ja pelastusopin merkitys väheni ja siirryttiin kohti terapeuttista eetosta, joka korostaa itsensä toteuttamista tässä maailmassa ja yksilön henkisen ja fyysisen terveyden merkitystä (Lears 1983; Wightman Fox \& Lears 1983). Terapeuttisen eetoksen mukainen huoli maallisen hyvinvoinnin säilyttämisestä ja itsensä toteuttamisesta antoivat hyvän kasvualustan kulutuskulttuurille sekä sitä levittävälle medialle ja mainonnalle.

Itsensä toteuttamisen, toimijuuden ja kontrollin kysymykset ovat keskeisiä myös Eeva Soinnun ja Linda Woodheadin (2008) ajatuksessa holistisesta hyvinvoinnista. Se voidaan nähdä yhtenä individualistisen henkisyyden (Heelas 2008) osa-alueena, joka painottuu kehollisiin menetelmiin. Holistisen hyvinvoinnin tavoitteena on voimaannutta yksilöitä sekä saada heidät ottamaan aktiivinen rooli ja vastuu elämänsä muuttamisesta. Soinnun ja Woodheadin mukaan Iso-Britanniassa 80 prosenttia holistisen henkisyyden toimijoista, joogasta aromaterapiaan, ovat naisia. Heistä valtaosa on valkoihoisia, hyvin koulutettuja ja taiteellis-humanistisesti orientoituneita. Holistisen hyvinvoinnin kuluttajaryhmä on siis hyvin selkeä, vaikkeivat palvelut itsessään ole sukupuolittuneita. Tutkijat näkevät selitykseksi sen, että holistinen henkisyys sekä vahvistaa että haastaa perinteisiä feminiinisyyden diskursseja: hoitaminen on perinteinen naisten työ, mutta huomio kääntyykin nyt elämästä toisia varten oman elämän vahvistamiseen, minkä nähdään kääntyvän myös lähimmäisten hyväksi. Samalla holis- 
tisessa henkisyydessä keho, terveys, ulkonäkö ja kokemukset nostetaan oikeutetusti huomion, huolenpidon ja kohentamisen kohteiksi.

Naisten kehon huoltamisen ja muokkaamisen halun syyksi voidaan nähdä myös kulttuuriset kauneusihanteet ja paineet jatkuvaan ulkonäön parantamiseen. Myös aikakauslehdet asettavat naisille täydellisen vartalon ihanteita: vaikka sisällöllisesti lehdissä käsiteltäisiin oman kehon rakastamisen tärkeyttä, muistuttavat kuvien mallit saavuttamattomasta ideaalivartalosta. (Mm. Bordo 1993; Markula 2001; Impett ym. 2006; Kyrölä 2010.) Aikakauslehtien kuvissa joogamallit ovat usein ihanteiden mukaisesti hoikkia ja lihaksikkaita. Myös monet jooganharjoittajat pitävät tervettä, hoikkaa ja voimakasta kehoa henkisen kehityksen symbolina, joka kertoo sekä mielen että kehon kurinalaisuudesta (Langøien 2012). Toisaalta joogaharjoitus ja holistinen ajattelutapa voivat toimia myös terveellisenä vastapainona naisiin kohdistuvia esineellistäviä odotuksia vastaan, koska ne korostavat vastuun ottamista omasta kehosta ja hyvinvoinnista (Impett ym. 2006).

Brittiläisen joogatutkija Suzanne Newcomben (2007) mukaan naisten osallistuminen terveyttä ja kauneutta edistävään liikuntaan, kuten joogaan, oli jo 1900-luvun ensimmäisen puoliskolla vakiintunut osaksi keskiluokkaisten naisten kulttuuria Englannissa. Joogaa markkinoitiin jo tuolloin mediassa terveyden ja kauneuden saavuttamisella. Aineistomme valossa voimme todeta, että terveyden ja kauneuden tematiikat eivät ole poissa muodista vieläkään, vaan ovat lähinnä laajentuneet kokonaisvaltaisen hyvinvoinnin piiriin.

\section{Jooga aikakauslehdissä}

Tarkastelemme joogan representaatioita seitsemässä suomalaisessa aikakauslehdessä: ET, Cosmopolitan, Hyvä terveys, Kodin Kuvalehti, Me Naiset, Sara ja Sport. Lehdistä on otettu talteen kaikki joogaan liittyvä toimituksellinen sisältö ja tekstit, joissa jooga mainitaan vuosilta 2008, 2009 ja 2010 sekä vuoden 2011 kuudelta ensimmäiseltä kuukaudelta. Aineistossa joogalla viitataan lähes poikkeuksetta edellä kuvattuun moderniin asentojoogaan. Kaikkien aineistoon valittujen lehtien taustalla on kaupallinen kustannusorganisaatio, joka tavoittelee mahdollisimman laajoja lukijakuntia tietyissä yleisösegmenteissä. Mainitut lehdet rahoittavat siis osan toiminnastaan mainostuloilla ja tavoittelevat kulutusmyönteisiä lukijoita. ${ }^{5}$ Lehtien ikä- ja elämäntapaprofiilit ovat vaihtelevia, joskin useiden lukijakunta koostuu pääosin naisista (Sanoma Magazines 2012). Varsinaisia naistenlehtiä joukosta ovat Cosmopolitan, Me Naiset ja Sara.

Analyysin painopiste oli laadullisessa lähiluvussa, mutta aineiston jäsentämiseksi käytimme aluksi määrällistä otetta (ks. Eskola \& Suoranta 2000, 164). Seitsemästä lehdestä kertyi kaikkiaan 161 tekstiä, joissa sana jooga esiintyy. Erittelimme kirjoitukset määrällisesti seitsemään luokkaan juttutyypin mukaan ja sen mukaan, miten jooga esiintyy teksteissä: 1) henkilöhaastattelut, 2) lajin esittely jossa 2a) jooga esiintyy osana kokonaisuutta tai 2 b) teksti keskittyy joogaan, 3) lajin harrastajan haastat- 
telu, 4) joogaopettajan haastattelu 4a) osana laajempaa kokonaisuutta tai 4b) omana juttunaan, 5) palsta/kolumni, 6) tuote-esittely (sisältää esim. asuste- ja mattovertailut sekä kirja- ja DVD-esittelyt), 7) jooga osana laajempaa juttukokonaisuutta.

Määrällistä sisällön erittelyä käytettiin antamaan suuntaa aineiston laadulliseen lähilukuun, jossa tarkasteltiin puhetta henkisyydestä ja kaupallisuudesta. Luonteeltaan kaupallisiksi luokittelimme jutut, jotka käsittelivät erilaisia joogapalveluja, kuten joogatunteja, retriittejä ja matkoja. Lisäksi laskimme tähän luokkaan jooga-asusteiden, kuten vaatteiden, kenkien ja joogamattojen, sekä joogaan liittyvien kirjojen ja DVD-levyjen arvioit ja esittelyt. Joissakin jutuissa joogaharrastus yhdistettiin jopa kosmetiikkatuotteisiin.

Tuloksena näkyi, että juttutyypeistä määrällisesti eniten joogaa käsitellään kolumneissa tai palstoilla (49/161 kpl). Toisinaan koko juttu käsittelee joogaa tai laji mainitaan esimerkiksi haastatellun henkilön harrastuksena tai osana tämän elämäntapaa. Vieraskirjoittajien kolumneissa käsitellään elämäntavan muutosta, johon kuuluu joogaharrastuksen aloittaminen ja kertomukset sen vaikutuksista. Kolumnien ja palstakirjoitusten määrästä lähes puolet (20 kpl) ovat pelkästään Sport-lehdestä, jossa vuodeksi joogan tielle Intiaan lähteneen toimittaja Virpi Mellerin kymmenen kolumnin sarja nimeltä Joogin vuosi saa runsaasti näkyvyyttä. Toiseksi eniten aineistossa on tekstejä, joissa jooga mainitaan vain osana muuta kokonaisuutta ( $40 \mathrm{kpl})$, esimerkiksi unettomuutta, selkäsärkyjä tai laihduttamista käsittelevissä jutuissa.

Kolmanneksi suurin yksittäinen luokka on joogaopettajien haastattelut (20/161 kpl), jotka kuitenkin painottuvat Sport, Me Naiset ja Hyvä Terveys -lehtiin. Joogan harjoitus tai harrastus tuodaan myös usein esiin osana henkilöhaastattelun kohteen elämää (16 kpl). Haastatteluissa näkyy niin tavallisia ihmisiä kuin julkisuuden henkilöitä, jotka harjoittavat joogaa. Kuuluisuuksien toimiminen joogan esiintuojina on ollut myös muualla länsimaissa merkittävää joogan suuren suosion kannalta. Esimerkiksi muusikko Pelle Miljoonan ja näyttelijä Jenny Banerjeen haastatteluissa joogan kerrotaan olevan osa heidän elämäntapaansa. Toisissa artikkeleissa jooga mainitaan vain ohimennen, kun kerrotaan haastateltavan vapaa-ajan harrastuksista. Mukaillen joogan harrastajakunnan sukupuolijakaumaa leijonan osa haastateltavista sekä kuvissa esiintyvistä malleista on valkoihoisia naisia.

Erityisesti urheiluun erikoistuneessa Sport-lehdessä moderni asentojooga näkyy erilaisissa urheilulajien, -välineiden ja -palveluiden esittelyissä ja vertailuissa. Tekstejä, joissa joogaan liittyvät tuotteet mainitaan ja jopa niiden hinta ja valmistaja ilmoitetaan, ilmenee aineistossa 65 kappaletta. Varsinaisia tuote-esittelyjä on vähän, mutta tuotteet ovat usein mukana toimituksellisen artikkelin tai kolumnin seassa. Kirja- ja DVD-arviot ovat oma luokkansa. Niissä on ilmoitettu teos, kustantaja ja hinta. Usein myös artikkeleiden taustalla on käytetty kirjaa tai käyty tutustumassa tiettyyn joogasaliin. Tällaiset toimituksen tekemät tuotteen kokeilujutut tai palvelupaikan esittelyt ovatkin naistenlehdissä ja erikoisaikakauslehdissä yleisiä.

Jooga näyttää aikakausilehtiaineiston valossa uineen sisään monenlaisiin keskusteluihin. Se esiintyy esimerkiksi naistenlehtien horoskoopeissa. Riippuen tähtimerkin asennosta lukijaa saatetaan esimerkiksi kehottaa hakeutumaan joogan pariin ren- 
toutumaan, rauhoittumaan tai etsimään henkisyyttä. Henkisyydestä kirjoitetaan 17 artikkelissa, ja myös siihen kytkeytyvistä meditaatiosta, hengitys- ja rentoutumisharjoituksista kirjoitetaan laajemmin. Valtaosassa aikakauslehtiaineistoa jooga representoidaan kuitenkin fyysisenä liikuntaharjoituksena, joka on koristeltu itämaisella eksotiikalla.

Valikoimme laadulliseen tarkasteluun aineistosta tekstit, joissa kirjoitetaan joogan henkisestä puolesta sekä joogaan liittyvistä palveluista ja tuotteista. Analyysin menetelmänä käytämme laadullista lähiluentaa, jota ohjaa teoreettinen käsiteapparaatti. Aineiston käsittelyssä olemme käyttäneet laadullisen aineiston analyysiin tarkoitettua Atlas.ti-ohjelmaa. Aineistoa on luettu useita kertoja lähiluennan menetelmän mukaisesti (esim. Miles \& Huberman 1994; Eskola \& Suoranta 2000, 174-180). Ensimmäisillä lukukerroilla teimme aineistosta havaintoja ja muistiinpanoja. Seuraavilla lukukierroksilla aloimme rajata ja eritellä aineistoa temaattisesti Atlas.ti:n koodaustoiminnon avulla, jolloin saman teeman löytäminen aineiston eri kohdista on mahdollista. Tämän jälkeen tarkistimme teemojen yhdenmukaisuutta ja niiden esiintymistä eri juttutyypeissä. Valitsimme teemoista tutkimuskysymyksen alueet eli henkisyyden ja kaupallisuuden teemat lähempään tarkasteluun ja analysoimme, miten niissä käytetyt puhetavat suhteutuvat yksilölliseen henkisyyteen ja naisvaltaiseen holistiseen hyvinvointiin.

\section{Ei aivan uskontoa, muttei pelkkää liikuntaakaan}

Aikakauslehtien kirjoittelussa joogan henkisistä vaikutuksista kirjoitetaan vuolaasti. Henkisyydellä tarkoitetaan useimmissa yhteyksissä kehon ja mielen kokonaisvaltaista hyvinvointia tai tasapainoa, johon myös Heelas ja Woodhead (2005) viittaavat individualistisella henkisyydellä ja Sointu ja Woodhead (2008) holistisella henkisyydellä. Esimerkiksi erilaisten liikuntalajien esittelyissä joogaa luonnehditaan avaimeksi psykofyysiseen hyvinvointiin: "Valitset sitten lajiksesi astangan, asahin tai vaikka bikramjoogan, saat seesteisen mielen ja hyvinvoivan kehon." (Sport 3/2008). Mainosmaiseen sävyyn joogaharjoituksen kerrotaan parantavan niin henkistä kuin fyysistä tasapainoa, keskittymiskykyä, mielen rauhaa ja läsnäolon taitoa.

Jooga luokitellaan lehdissä niin kutsuttuihin keho \& mieli -lajeihin, joissa korostetaan kehon ja mielen yhteyttä, kehotietoisuutta ja kehon kuuntelua. Keho \& mieli -lajeissa myös hengityksellä on keskeinen tehtävä, sillä sen katsotaan toimivan mieltä ja kehoa yhdistävänä tekijänä. Jooga erotetaan muista lajeista korostamalla harjoituksen henkistä ulottuvuutta ja tarinaa joogan eksoottisesta intialaisesta alkuperästä. Samalla kuitenkin usein alleviivataan joogan ei-uskonnollisuutta. ET-lehden reportaasissa pohditaan laajemmin joogan olemusta sekä sen henkistä ja maallista puolta. Jutussa haastatellaan muun muassa uskontotieteen dosentti Måns Broota, joka on kääntänyt sanskritin kielestä suomeksi klassisia joogatekstejä ja päätoimittaa joogalehti Anandaa: 
Måns Broon mukaan useimmat hakevat joogasta parempaa kuntoa ja rauhoittumista eli ihan maallisia asioita.

- Jos tavoittelee niitä, ei muuta saa. Joogassa ei voi käydä niin, että lähtee hakemaan vain tiukempaa takapuolta ja päätyykin hinduksi. Jooga ei ole uskonto, vaikka se lähteekin uskonnollis-filosofiselta pohjalta. Muinoin se oli lähinnä henkinen harjoitus, nykyisin se mielletään ennen muuta ruumiilliseksi.

Joogaaja huomaa kuitenkin pian, miten lähellä keho ja mieli ovat toisiaan. Vaikka joogalla hoitaisi kroppaansa, samalla tulee kiinnostuneeksi myös mielestä. Kaikkien joogamuotojen yhteinen päämäärä on mielen toimintojen pysäyttäminen. Silloin mieli lepää ja ihminen voi tavoittaa puhtaan tietoisuuden tilan.

(ET 11/2011.)

Ote ilmentää hyvin moderniin joogaan liittyvää ristiriitaa. Yhtäällä jooga esitetään kuntoilulajina, jolla pyritään kohentamaan ulkonäköä, tavoitellaan "tiukempaa takapuolta". Toisaalla jooga kuitenkin esitetään henkisenä harjoituksena. Broo toteaa, että "jooga ei ole uskonto, vaikka se lähteekin uskonnollis-filosofiselta pohjalta", viitaten joogan juuriin hindulaisessa asketismissa. Tämä puhetapa on tyypillinen koko aikakauslehtiaineistossa. Uskonnon ja henkisyyden eroa halutaan selvästi korostaa - ilmeisesti pelätään, että se karkottaisi ei-uskonnollisia harrastajia tai lukijoita. Aikakauslehtien kaupallisen toimintamallin mukaisesti ne tavoittelevat mahdollisimman laajoja lukijakuntia ja pyrkivät siksi miellyttämään enemmistöä. Uskonnon ja henkisyyden eroa alleviivataan myös seuraavassa otteessa Me Naiset -lehden joogaopettajan haastattelussa:

Joogaan liitetään voimakkaasti myös uskonnollinen aspekti. Vaikka hot joogassa ei lauleta mantroja, Harriet kokee, että henkinen puoli on merkittävä.

- Jooga ei ole uskonnon harjoittamista, mutta se on enemmän kuin liikuntaa.

(Me Naiset 30.4.2008.)

Artikkelissa todetaan aluksi, että "joogaan liitetään voimakkaasti myös uskonnollinen aspekti", mutta joogaopettajan sitaatissa tämä välittömästi kiistetään: "jooga ei ole uskonnon harjoittamista". Kieltoa seuraava lieventävä toteamus "mutta se on enemmän kuin liikuntaa" on oleellinen, sillä se toistuu muuallakin aineistossa. Joogaa ei tässä haluta määritellä uskonnoksi, mutta kuitenkin sitä pidetään "henkisenä" lajina. Haastattelun lopussa joogaopettaja jatkaa: "Opettajana haluan antaa oppilailleni elämyksiä, kannustaa heitä puskemaan itseään pidemmälle ja voittamaan itsensä, Harriet sanoo." (Me Naiset 30.4.2008.) Tässä joogan katsotaan antavan mahdollisuudet holistisen hyvinvoinnin mukaiseen yksilölliseen itsensä toteuttamiseen ja muutokseen (vrt. Lau 2000; Sointu \& Woodhead 2008).

Jooga siis määritellään aineistossa yhtä aikaa sekä "ei-uskonnoksi" että "ei-liikunnaksi". Suhteessa uskontoon se on jotain yksilöllistä ja suhteessa liikuntaan jotain "enemmän". Tämän ambivalenssin taustalla näyttää vaikuttavan Heelasin ja Woodheadin (2005) tekemä erottelu "ulkoa määräytyneen" uskonnollisuuden ja individu- 
alistisen henkisyyden välillä. Joogaa myös kutsutaan aineistossa "filosofiaksi", jolloin yksilölle jää enemmän vapautta määritellä se haluamallaan tavalla.

\section{Henkisyyden kaupallisuus}

Useissa aineiston teksteissä jooga esitetään fyysisenä ja mieltä rauhoittavana lajina. Silti kuvituksessa näkyy uskonnon harjoittamiseen liittyvää symboliikkaa. Esimerkiksi Me Naiset -lehden (21.12.2010) Hyvä Fiilis -palstan solarjoogan esittelyssä kerrotaan 31-vuotiaan Elina Verten talviaamusta 30 asteisella joogasalilla, jossa käytetään kirkasvalolamppuja. Teksti kuvailee hyvin maallisesti salin tunnelmaa, harjoituksen etenemistä ja siitä tulevaa hyvää oloa. Kuitenkin kuvassa näkyy nainen istumassa stereotyyppisesti joogaa esittävässä risti-istunnassa. Hänen kämmenensä ovat tietynlaisessa mudra-asennossa ja pää on kallistunut alas kohti sydäntä. Asento viestii meditaatiosta. Taustalla näkyy Buddha-patsas.

Vielä ilmeisemmin vastaava ristiriita näkyy Me Naiset -lehden artikkelissa 29.7.2010, jossa korostetaan, kuinka ulkonäöstä huolehtiminen kosmetiikkatuotteilla on tärkeää myös tennistä pelatessa, juostessa, uidessa ja joogasalilla. Eri lajien harrastajalle on tässä valittu omat meikit ja ihonhoitotuotteet. Joogan harrastajalle suositellaan muun muassa talkkia ja luonnonmukaisia kasvovoiteita. Tekstin sanoma on puhtaan kau-

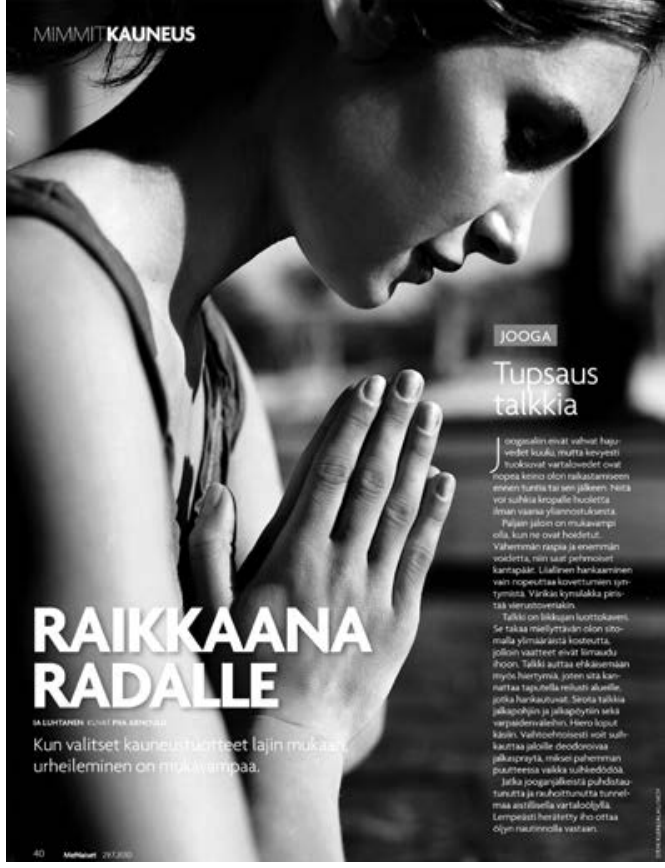

Kuva 1. "Raikkaana radalle" -artikkeli urheilulajeihin sopivista kosmetiikkatuotteista, Me Naiset 29.7.2010. pallinen, mutta jutun avauskuvassa näkyy joogaa harrastava nainen pää alasluotuna ja kädet yhteenliitettyinä sydämen edessä niin kutsutussa namaskar-tervehdysasennossa. Antropologi ja hindulaisuuden tutkija Christopher Fullerin (1992) mukaan ele ilmentää jokaisen ihmisen jumalallista luonnetta: hindulaisuudessa ihmisten ja jumalten välillä ei tehdä absoluuttista eroa. Tervehtimisen tapakulttuurin lisäksi symboliin liittyy siis tietty hartauden elementti. Joogaharjoituksessa asentoa käytetään muun muassa jokaisen itsensä sisällä olevan sekä ulkopuolella olevien opettajien eli gurujen kunnioittamisen eleenä.

Kaupallisuus on vahvasti ja avoimesti läsnä aineiston joogaaiheisissa kirjoituksissa. Yleisin joogakuluttajan puhuttelun tapa 
on erilaisten tuotteiden esittelyt, jotka liittyvät suoraan joogan harjoitukseen tai joissa joogaharrastus on taustalla kuvittamassa tuotteen käytön ympäristöä ja merkitsemässä tuotteen kohderyhmän elämäntapaa - kuten edellä Me Naisten joogaharrastajan meikkivinkeissä. Suoraan joogaan liittyviä tuotteita ovat yleisimmin joogamattojen esittelyt ja vertailut, kirja- ja DVD-arviot. Esimerkiksi ET-lehden jooga- ja jumppa-asusteiden esittelyssä puhutellaan joogakuluttajaa näin:

Kaipaako kehosi lempeää venyttelyä, kunnon hikitreenin vai molempia? Kivat vaatteet ja hyvät välineet innostavat harrastamaan. Jooga-asuissa korostuvat pehmeys, lämpö ja joustavuus. Jumppavaatteiden on oltava kestäviä, käytännöllisiä ja hengittäviä.

(ET 13/2008.)

Teksti antaa ymmärtää, että oikeanlaiset vaatteet ja välineet ovat oleellinen osa harrastusta ja kehottaa joogan harrastajaa hankkimaan pehmeitä ja joustavia asusteita. Aineistossa toistuvat myös erilaisten kuntoilulajien vertailut, joissa on taulukoitu lajin vaativuutta ja muita ominaisuuksia.

Aineistossa on artikkeleita erilaisista kuntoilijatyypeistä, ${ }^{6}$ joille annetaan tarkempia ohjeita esimerkiksi viikoittaisen harjoitusohjelman laatimiseen. Me Naiset -lehden artikkelissa lukijaa kehotetaan tunnistamaan oma liikuntalajinsa: tekstissä kysytään lukijalta, onko hän "tanssiva kuntoilija”, "tiukka puurtaja” vai "henkinen liikkuja". Tämäntapainen kuluttajasegmenttien luokittelu on ominaista promootiokulttuurin (Wernick 1991) viestinnälle. Lehdet segmentoivat lukijaryhmiä, jotta ne voivat saada mainostajat ja tuotteiden valmistajat mukaan toimituksellisen sisällön rahoittamiseen. Kaupallinen media toimii myymällä yleisöjä mainostajille (mm. Ang 1991). Me Naisten artikkelissa henkinen liikkuja määritellään sellaiseksi, jolle "liikunta on terapiamuoto, pyrkimystä kehon ja mielen harmoniaan". Henkisen liikkujan lajeiksi listataan joogan eri muodot: taiji, pilates, shindo, asahi-venyttely, chi kung ja feldenkrais. Henkisen liikkujan kerrotaan olevan "rauhaa rakastava kuntoilija", joka pitää "filosofioista lajien takana". Teksti sinuttelee lukijaa kauttaaltaan: "Sinulle treeni on muutakin kuin kehonmuokkausta, haluat vahvistusta myös mielelle." Kuitenkin kehoon ja ulkonäköön liittyvät seikat hallitsevat henkiseksi liikkujaksi luokitellun haastateltavan sitaatissa, jossa 35-vuotias nainen "todistaa", miten jooga on muuttanut hänen elämäänsä:

Kun aloitin joogan, huomasin uudenlaisen rentouden koko kropassa. Hartiat kirjaimellisesti tippuivat korvista alaspäin. Myös allit lähtivät ryminällä, kun käsien ojentajalihakset saivat jooga-asennoissa harjoitusta. Punnerrukset ovat tuoneet spagettikäsivarsiini kiinteät ja solakat lihakset. Seisten tehtävät asennot kiinteyttävät tehokkaasti alavartaloa. Myös selluliittia on hävinnyt fyysisen harjoituksen myötä.

Nainen, 35, harrastaa dynaamista joogaa.

(Me Naiset 28.8.2008) 
Henkistä liikkujaa kuvaavan tekstin ohessa on piirroskuva toisiaan vasten olevista sukista, jotka ilmentävät jalkapohjat yhdessä pidettävää jooga-asentoa (baddhakonasana). Sukkien yläpuolella leijuu sädekehä, yksinkertaistettu symboli, joka ammentaa pikemmin kristillisestä visuaalisesta perinteestä, mutta viittaa nimenomaisesti henkisyyteen. Tässä esimerkissä henkisyys tuotteistetaan joogan ominaisuudeksi ja sen avulla se voidaan erottaa muista kuntolajibrändeistä.

Joogapalveluita brändätään toistuvasti artikkeleissa, joissa lehden toimittaja on käynyt tutustumassa palveluntarjoajan salilla ja kokeilee joogatuntia tai muuta liikuntapalvelua. Esimerkiksi Hyvä Ter-

\section{Henkinen liikkuja}

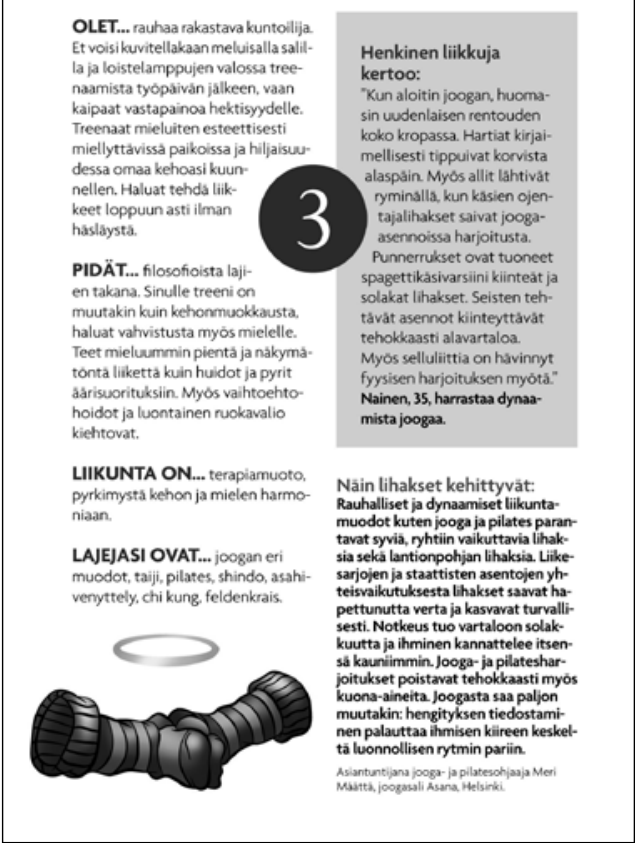

Kuva 2. Ote Mimmit kuntoon -palstan kuntoilijaluokittelusta. "Liikkumalla lihaksia", Me Naiset 28.8.2008. veys -lehdessä on esitetty taulukkovertailu eri liikuntalajeista, lokeroiden otsikkoina ovat "mitä on", "miltä tuntui", "kenelle" ja "hinta". Lukijalle tarjotaan mahdollisuutta tunnistaa itsensä jonkin lajin harrastajaksi ja häntä kehotetaan hakeutumaan palveluiden tarjoajien luokse. (Hyvä terveys 1/2010.)

Jokaisen joogalajin yrittäjät pyrkivät erottumaan massasta ja houkuttelemaan omanlaisiaan asiakkaita. Aineisto ilmentääkin erilaisten joogamuotojen kirjoa. Esimerkiksi Hormonijooga on yksi uusimmista joogan paketointimuodoista. Yksilöidysti poimittu hormoni-sana auttaa brändäämään tietynlaisen joogaharjoituksen ja suuntaamaan sen erityisesti vaihdevuosi-iässä oleville naisille. Hormonijoogasta saamme lukea esimerkiksi Sara-lehdestä 3/2011, jossa haastatellaan espoolaista 54-vuotiasta Päivi Johanssonia, joka "oli viime vuoden vuorotteluvapaalla päättänyt pyhittää lomansa itsensä hoitamiseen". (Ks. myös Puustinen 2013.)

Jooga määritellään aineistossa useimmiten kokonaisvaltaista hyvinvointia ja mielenrauhaa lisääväksi liikuntamuodoksi. Sport -lehden (2008/3) artikkelissa kirjoitetaan, että "tuhansia vuosia sitten Intiassa syntyneellä joogalla on ollut aina useita suuntauksia. Niillä kaikilla on yhteinen tavoite: ihmisen henkinen kasvu ja kokonaisvaltainen hyvinvointi." Tässä sekä joogan pitkää historiaa että henkisyyttä käytetään brändäämään jooga tietynlaiseksi liikuntamuodoksi. Jooga esitetään tuotteena, joka voisi sellaisenaan tuoda ostajalleen toivottuja ominaisuuksia kuten mielenrauhaa. 
Puhetapa toistuu esimerkiksi jooga-aiheisten kirjojen esittelyissä. Sport lukee -palstalla puffataan lyhyesti jooga-opaskirjan tarjoavan pika-apua ahdistukseen ja stressiin:

Joogaa ahdistus pois

Sehän ei pidemmän päälle toimi, että yrittää suorittaa elämäänsä niskat pinkeinä kiireestä ja stressistä paukkuen. Ehei, sellaiselle touhulle pitää laittaa stoppi. Sport kokeili pikamatkaa nirvanaan kolmen minuutin rentoutusohjelmalla, ja kas! Olo helpottui kummasti, Joogaa ja nauti -kirjan muidenkin rentouttavien ja mieltä tasapainottavien ohjeiden noudattaminen onnistui myös aivan aloittelevalta joogilta.

Tara Fraser: Joogaa ja nauti, Helppoja, tehokkaita ja kiinteyttäviä ohjeita, 17,10 e. Helmi. (Sport 3/2008)

Joogan esitetään tässä tarjoavan kiireiselle nykyihmiselle pikaruoan tavoin nopeaa tarpeen tyydytystä ja helpotusta arjen ongelmiin. Aineistosta kuitenkin käy ilmi, että joogan brändäämisessä tärkeimmät tekijät ovat ulkonäkö, psykofyysinen hyvinvointi, rentous, terveys ja stressin vähentäminen. Ne menevät selvästi henkisyyden edelle joogatuotteiden ensisijaisina myyntivaltteina. Tämän havainnon on tehnyt myös Kimberly Lau (2000) amerikkalaisen mediatarjonnan osalta. Carretten ja Kingin mukaan joogan henkiset ja etenkin selkeästi hindulaisuuteen liittyvät piirteet on länsimaissa karsittu minimiin (Carrette \& King 2005). Aikakauslehtiaineistossa ne toimivat lähinnä "mausteina", jotka luovat tietynlaista mielikuvaa joogasta.

\section{Henkinen kasvu ja elämänmuutos - vastavoima kulutuskulttuurille?}

Huolimatta siitä, että jooga esitetään aineistossa usein kaupallisessa kontekstissa, näkyy siellä myös joitakin kulutuskulttuuria ja kilpailuyhteiskuntaa kritisoivia näkemyksiä. Näitä poikkeuksia löytyy kuitenkin ainoastaan kahdessa seitsemästätoista joogapalvelua käsittelevästä jutusta. Myös joogan harjoittajien elämänmuutoksiin ja henkiseen kasvuun viittaavat artikkelit voidaan nähdä sisältönsä puolesta usein kulutuskulttuurista poikkeavina.

Vastoin kaupallisuuden valtavirtaa Sport-lehden (1/2009) artikkeli kertoo erilaisista liikuntalajeista, "jotka eivät vaadi latin latia sen jälkeen, kun olet hankkinut varusteet". Tässä jooga esitetään lajina, joka ei vaadi taloudellisia investointeja, ja se mainitaan listassa koti-etuliitteellä ("kotijumppa, -pilates, -jooga ja -venyttely") kävelyn, juoksun, hiihdon, pyöräilyn ynnä muiden joukossa. Jutussa kerrotaan myös kuntien ilmaisesta liikuntatarjonnasta.

Kaupallisuuden kritiikkiä esiintyy myös odottamattomissa yhteyksissä. Sport-lehden (9/2008) "Opas Helsingin urheilukauppoihin" artikkelin ingressi alkaa kehotuksella kuluttamaan: "Paikoillanne, valmiina, shoppaamaan!" Jutussa kysellään julki- 
suuden henkilöiltä, mistä he hankkivat liikuntavaatteensa. Näyttelijä Minna Haapkylä vastaa:

Joogaan kotona pitkissä kalsareissa ja virttyneessä t-paidassa. Minulle kirpparit ovat tärkeimpiä joogavaatteiden ostospaikkoja. Tosin haaveilen upouudesta ja lajiin tarkoitetusta asusta, mutta sellainen on niin kallis, että kalsarit saavat kelvata toistaiseksi. Joogamaton hankin Joogakaupasta Fredrikinkadulta. [...]

(Sport 9/2008.)

Haapkylän kommentti poikkeaa muista artikkelin haastatteluista, ja siinä voidaan tulkita vastarintaa lehden toimittajan pyrkimykselle asettaa hänet ulkonäkökeskeiseksi julkkikseksi. Hän kuitenkin myöntää haaveilevansa "upouudesta lajiin tarkoitetusta asusta" ja kertoo hankkineensa joogamaton Joogakaupasta. Tässä Haapkylä palaa toimittajan asettamalle kuluttamiseen kannustavalle linjalle. Lopussa ilmoitetaan Joogakaupan osoite, jotta lukija tietää, mistä lajiin tarkoitettuja välineitä voi ostaa. Näyttää mahdolliselta, että joogan representaatioissa esiintyvä kaupallinen painotus kertoo enemmän aikakauslehtien kaupallisista intresseistä kuin joogan kaupallisuudesta sinänsä.

Kulutuskulttuuria kritisoivia kommentteja löytyi myös parista henkilöhaastattelusta. Terveys-lehden (2/2008) haastatteleman, tunnetun astangajoogaopettaja Juha Javanaisen kerrotaan pitävän joogaa vastavoimana "kovalle bisneshenkiselle kilpailulle". Myös entisen Ultra Bra -yhtyeen laulaja ja näyttelijä Vuokko Hovatta kertoo Terveys-lehdessä (8/2010) rakastavansa joogaa, "koska siinä ei voi ylisuorittaa". Tässä puhetavassa korostetaan sitä, että toisin kuin työelämässä, joogassa ei pyritä suorittamaan.

Sport-lehden (11-12/2010) reportaasissa kerrotaan kahden helsinkiläisen joogaopettajan uudesta studiosta, jonka liikeideassa on hyväntekeväisyyttä. Salin tuotosta kymmenen prosenttia menee orpokodin perustamisen rahoittamiseen Intiassa. Juttu kertoo siitä, miten idea yhdistää kaupallisuuden ja hyväntekeväisyyden monella tapaa. Joogayrittäjien tavoitteena on, että asiakas saa itselleen hyvinvointia joogatunneista ja osallistuu samalla hyväntekeväisyyteen. Tämä on esimerkki joogan moraalisten periaatteiden niveltymisestä kaupallisessa kulttuurissa harjoitettuun liiketoimintaan. Artikkelissa esitetään, että tekijät ovat nyky-yhteiskunnan pelisäännöistä ja joogan periaatteista hyvin perillä ja pyrkivät sovittamaan näitä yhteen. Jooga ja henkisyys artikuloituvat tässä kulutuskulttuuriin uudella tavalla, jossa korostuu tietoisuus näiden kahden maailmojen yhteensovittamisen ongelmista.

Aikakauslehtiaineistossa jooga liitetään usein henkiseen kasvuun ja elämänmuutokseen holistisen hyvinvoinnin aatteiden mukaisesti. Joogan kerrotaan auttaneen huonojen elämäntapojen, kuten tupakoinnin ja alkoholin käytön lopettamisessa (esim. Me Naiset 8/2009). Myös ruokavalion muutokset ja television katselun lopettaminen mainitaan. Joogan kerrotaan usein myös auttaneen kuntoutumisessa onnettomuuden tai sairauden jälkeen ja sen avulla voidaan lievittää esimerkiksi vaihdevuosivaivoja (esim. Sara 4/2010 ja 3/2011). Joogan kerrotaan auttavan myös astmaan 
ja unettomuuteen (Sport 1/2008). Yleisesti jutuissa kerrotaan elämänarvojen muuttuneen joogan myötä, esimerkiksi $E T$-lehdessä on haastateltu useita iäkkäitä joogan harrastajia, jotka mainitsevat niin henkisiä kuin fyysisiä muutoksia:

Kun Leena Weckström oli harjoittanut astangaa säännöllisesti useamman kuukauden ajan, muutokset alkoivat tuntua. Niitä tapahtui sekä vartalossa että mielessä. Harjoitusten edetessä myös Leenan elämänarvot alkoivat muuttua kuin itsestään. Hän siirtyi kasvisruokavalioon eikä enää edes haluaisi syödä lihaa tai roskaruokaa. Alkoholikin jäi pois lähes kokonaan.

- Elämäni on nykyisin pääosin töitä ja joogaa. En kaipaa paljon muuta sen lisäksi. En haali omaisuutta ja yritän auttaa muita. Henkiset arvot ohjaavat elämääni, ei raha.

(ET 11/2011.)

Sitaatissa on poikkeuksellista, että henkiset arvot esitetään rahan vastakohtana. Useimmiten joogasta kertovissa jutuissa ei näy tätä ristiriitaa, vaan jooga-asentoohjeet, joogavaatteet, kauneus- ja laihdutusvinkit lomittuvat sulassa sovussa henkisyyden rinnalle. Henkisen kasvun ja elämänmuutoksen tematiikka tukee voimakkaasti Paul Heelasin (2008) väitettä, että individualistisen henkisyyden ja kaupallisuuden läheinen suhde ei tarkoita, että henkisyyteen liittyvien aktiviteettien merkitys voitaisiin kokonaan palauttaa kaupallisuuteen. Moderni asentojooga näyttää aikakauslehtiaineiston perusteella tuottavan harjoittajilleen kokemuksia ja vaikutuksia, jotka kyseenalaistavat kulutuskulttuurin mekanismit. Aineisto tukee Paul Heelasin toteamusta, jonka mukaan individualistiseen henkisyyteen liittyvät aktiviteetit auttavat irrottautumaan välineellisestä ja päämääräsuuntautuneesta ajattelusta ja ruokkivat toisenlaista elämänasennetta, jota Heelas (2008) nimittää humanistis-ekspressivististen arvojen kokonaisuudeksi (humanistic-expressivistic value complex). Aikakauslehtiaineiston valossa näyttääkin siltä, että huolimatta individualistisen henkisyyden ja kaupallisuuden voimakkaista yhteyksistä, voivat joogan kaltaiset henkiset aktiviteetit ruokkia harjoittajissaan myös kulutuskriittisiä näkemyksiä.

\section{Johtopäätökset}

Aikakauslehtiaineiston representaatioissa joogasta korostuu fyysinen harjoitus, jolla tavoitellaan kauneutta ja terveyttä. Toisaalla näkyy myös puhe siitä, että jooga on "enemmän kuin liikuntaa", se tähtää kehon ja mielen tasapainoon. Jooga määritellään erityisesti henkiseksi lajiksi. Mutta on tyypillistä korostaa, ettei jooga ole uskonto, vaan filosofia. Tämä puhe tuottaa Paul Heelasin (2008) määrittelemää individualistista henkisyyttä, jossa yksilöllä on vapaus määritellä henkisyyden sisältö ja jossa korostetaan kokonaisvaltaista psykofyysistä hyvinvointia.

Aineistossa on vahvasti esillä myös joogan välineellistämisen mahdollisuus. Materiaali kuvaa monin tavoin, kuinka joogaharjoitusta voi käyttää eri tavoin holistisen hyvinvoinnin (Sointu \& Woodhead 2008) välineenä tai tekniikkana - henkisyydellä 
tai ilman, vailla pelkoa uskonnollisesta hurahtamisesta tai laajemmasta elämäntapamuutoksen vaateesta. Erityisesti henkilöhaastattelujen kautta nousee kuitenkin esille, kuinka joogan harjoittaminen voi muuttaa elämää positiivisesti ratkaisevalla tavalla. Lukijalle jätetään aina yksilöllinen valinnan mahdollisuus tulkita ja harjoittaa joogaa haluamallaan tavalla.

Joogaa käsitellään aikakauslehdissä valtaosin kaupallisessa kontekstissa. Joogan henkisiä piirteitä ei tavallisesti korosteta, joskin henkisyys ja uskonnollinen symboliikka ovat usein läsnä kuvituksessa. Henkisyydellä ja "vuosituhansia vanhalla" intialaisella perinteellä joogaa myös strategisesti differentoidaan eli eriytetään muista liikuntalajibrändeistä ja sille tuotetaan oma kuluttajasegmentti. Joogan myyntivalteiksi nostetaan terveys, stressin vähentäminen, psykofyysinen hyvinvointi eli "kehon ja mielen yhdistäminen" ja erityisesti se, miten kaikki nämä parantavat ulkomuotoa. Tämä myös perustelee lukijoille monenlaisten oheistuotteiden markkinoinnin naisvaltaiselle yleisölle joogaa käsittelevien artikkelien yhteydessä.

Kaupalliset aikakauslehdet luovat ja vahvistavat mielikuvia paitsi joogan ja siihen liitettävien oheispalvelujen hyödyistä. Ne tuottavat tietynlaista kuvaa myös ihanteellisesta joogan harjoittajasta, joka on elinvoimainen, arjen kiireistä huolimatta harmoninen, tässä maailmassa elävä ja itseään toteuttava yksilö. Joogaan liittyvä subjekti esitetään sopusoinnussa vallitsevaan yhteiskuntajärjestykseen, kaupalliseen mediakulttuuriin. Psyykkisen ja fyysisen ulottuvuuden korostaminen heijastaa individualistisen henkisyyden ja hyvinvointikulttuurin taustalla vaikuttavaa kapitalismin ja modernin psykologian liittoa (Carrette \& King 2005).

Kimberly Laun (2000, 126) mukaan joogaharjoitusohjeita annetaan naistenlehdissä, jotta naiset voisivat laihduttaa, hoitaa kauneuttaan ja ilmentää naiseuttaan. Lau kirjoittaa, kuinka naistenlehdet tarjosivat menneinä vuosikymmeninä aerobic- ja jumppaohjeita, joiden esitettiin edistävän kauneutta ja hyvinvointia fyysisesti rankalla harjoituksella. Jooga ja muut keho \& mieli -lajit ovat tulleet näiden tilalle. Uudet menetelmät ovat pehmeämpiä, mutta niiden takana oleva kauneutta, seksuaalisuutta ja sukupuolta korostavat ideologia on yhä sama.

Elämänarvojen muutoksen ja henkisen kasvun teemojen esiintyminen aineistossa tukee kuitenkin myös Paul Heelasin (2008) näkemystä, jonka mukaan individualistista henkisyyttä ja hyvinvointikulttuuria ei voida täysin palauttaa kapitalistisen kulutuskulttuurin ilmentymäksi. Joogan esimerkiksi kerrotaan tarjoavan vaihtoehdon kilpailulle, huonoille elämäntavoille ja materialismille. Aineiston harvoissa tapauksissa tarjotaan myös vaihtoehtoja kulutuskulttuurille ja ruokitaan jopa kulutuskriittisiä näkemyksiä. Kaupallisuuden korostuminen johtunee aikakauslehtien luonteesta, ja siksi olisikin tarpeellista jatkaa tutkimusta paitsi laajemman media-aineiston myös joogan harrastajien ja joogaopettajien haastatteluiden valossa.

Kulutuksen tutkijat (mm. Wightman Fox \& Lears 1983, xiii) kirjoittavat, että kulutuskulttuuri on tunkeutunut kaikille elämän alueille: uskontoon, mediaan, kirjallisuuteen, yhteiskuntatieteisiin, politiikkaan ja hallintoon. Kulutuksesta on tullut ideologia, tietynlainen uskonto, joka ohjailee niin sosiaalisia instituutioita kuin ihmisten arkista elämää. Toisaalta myös uskonto tai henkisyys muuttaa muotoaan aikakausien ja kult- 
tuurien mukaan (esim. Taira 2006). Henkiset ja uskonnolliset liikkeet käyttävät aikakautensa viestintämuotoja pyrkiessään kasvattamaan jäsenkuntaansa ja legitimoimaan omaa maailmankuvaansa. Voidaan siis kysyä, käyttävätkö joogan toimijat kaupallisuutta ja mediaa hyväkseen ideologiansa levittämiseen vai käyttääkö kaupallinen kulttuuri joogaa saavuttaakseen taloudellista voittoa. Toisaalta joogalajit korostavat fyysiseen materiaaliseen kulttuuriin sopivaa fyysistä harjoitusta, jolloin liikunnallisuutta käytetään joogan myyntivalttina ja sen ohella voidaan levittää vähitellen myös henkistä sanomaa. Toisaalta kaupallinen media tuotteistaa joogan henkisyydellä ja intialaisella toiseuden eksotiikalla brändätessään uutta liikuntalajia ja tavoitellessaan massayleisöjen huomiota. Tutkimuksemme valossa näyttää siltä, että joogan tapauksessa henkisyys ja kaupallisuus hyödyntävät toinen toisiaan.

Kiitokset Jenna Parmalalle aineiston keruusta sekä lehtien ET, Cosmopolitan, Hyvä Terveys, Kodin kuvalehti, Me Naiset, Sara ja Sport päätoimittajille aineiston luovuttamisesta tutkimuksen käyttöön.

\section{Viitteet}

1 YLE verkkouutiset (23.10.2008). Suomalaiset ovat kovia joogaamaan. http://yle.fi/uutiset/ suomalaiset_ovat_kovia_joogaamaan/6116323 http://olotila.yle.fi/mina/hyvinvointi/suomalaisetovat-kovia-joogaamaan.

2

"Notkea moderni" on sosiologi Zygmunt Baumanin luoma käsite, jolla hän viittaa nykyajan valikoivaan ja yksilökeskeiseen kulttuuriin. Käsite on enemmän tai vähemmän synonyyminen "postmodernin" (Lyotard), "myöhäismodernin" (Giddens) ja "toisen modernin" (Beck) kanssa. (Ks. Taira 2006.)

3 Oikeudenkäynti jatkuu yhä, mutta 14.12.2012 annetun päätöksen mukaan näyttäisi siltä, että Choudhury menettää oikeuden kyseisen sarjan tavaramerkkioikeuteen (Bloomberg 17.12.2012). http://www.bloomberg.com/news/2012-12-17/yoga-astrazeneca-intel-un-intellectual-property.html (luettu 21.3.2013)

4 Suomessakin talkoohengessä toimivalla Suomen Joogaliitolla sekä työväenopistoilla ja vastaavilla yleissivistävillä laitoksilla on ollut ja on yhä keskeinen rooli joogan leviämisessä ja opetuksen tarjonnassa kautta maan.

$5 \quad$ Aikakauslehdet ovat rakentuneet kulutusretoriikalle jo niiden alkuajoista 19oo-luvun vaihteesta lähtien, ja niiden yhteys kapitalistiseen tuotantoon ja kulutukseen on edelleen vahva (mm. Wilson 1983; Gough-Yates 2003). Tutkimuksemme ei ole kuitenkaan varsinaista aikakauslehtitutkimusta, eli aikakauslehtimedian erityisluonteeseen ei tässä ehditä paneutua (ks. Töyry, Saarenmaa \& Särkkä 2011). Lehtiaineiston tehtävä on pikemmin toimia tapausesimerkkinä alueesta, jossa tuotetaan kulttuurisia representaatioita joogasta.

6 Huomionarvoista on myös kuinka paljon raflaavampia naistenlehtien tuottamat kategoriat ovat kuin esimerkiksi Suomen Kuntoliikuntaliiton (2010) tutkimuksessa: kilpaurheilija, kuntourheilija, kuntoliikkuja, terveysliikkuja, arki-ja hyötyliikkuja, satunnaisliikkuja ja liikunnallisesti passiivinen. 


\section{Kirjallisuus}

Ang, len (1991). Desperately seeking the audience. London: Routledge.

Bordo, Susan (1993). Unbearable weight: Feminism, western culture, and the body. Berkeley: University of California Press.

Carrette, Jeremy \& King, Richard (2005). Selling spirituality: The silent takeover of religion. London: Routledge.

De Michelis, Elizabeth (2004). A history of modern yoga: Patañjali and western esotericism. Cornwall: Continuum.

Eskola, Jari \& Suoranta, Juha (2000). Johdatus laadulliseen tutkimukseen. Tampere: Vastapaino.

Fuller, Christopher (1992). The camphor flame: Popular Hinduism and society in India. Princeton: Princeton University Press.

Gallup Ecclesiastica (2011). Kirkon tutkimuskeskuksen julkaisuja.

Giordan, Giuseppe (2007). Spirituality: From a religious concept to a sociological theory. Teoksessa: Flanagan, Kieran; Jupp, Peter C. (toim.). A sociology of spirituality. Burington, VT: Ashgate, 161-180.

Gough-Yates, Anna (2003). Understanding women's magazines: Publishing, markets and readerships. London, New York: Routledge.

Hasselle-Newcombe, Suzanne (2005). Spirituality and 'mystical religion' in contemporary society: A case study of British practitioners of the lyengar method of yoga. Journal of contemporary religion 20:3, 305-321.

Heelas, Paul (2008). The spiritualities of life: New age romanticism and consumptive capitalism. Malden, MA: Blackwell.

Heelas, Paul; Woodhead, Linda; Seel, Benjamin; Szerszynski, Bronislaw \& Tusting, Karing (2005). The spiritual revolution: Why religion is giving way to spirituality. Malden, MA: Blackwell.

Impett, Emily; Daubenmier, Jennifer \& Hirschman, Allegra (2006). Minding the body: Yoga, embodiment, and well-being. Sexuality research $Q$ social policy 3:4, 39-48.

Jain, Andrea R. (2012). Branding yoga: The cases of lyengar yoga, Siddha yoga and Anusara yoga. Approaching religion 2:2, 3-17.

Ketola, Kimmo (2001). Uudet uskonnolliset liikkeet: Katsaus käsitteisiin, luokituksiin, teorioihin ja tilastoihin. Teoksessa: Niemelä, Jussi (toim.) Vanhat jumalat, uudet tulkinnat: Näköaloja uusiin uskontoihin Suomessa. Uskontotiede 6, Helsinki: Helsingin yliopiston uskontotieteen laitos, $10-38$.

Kyrölä, Katariina (2010). The weight of images: Affective engagements with fat corporeality. Turku: Turun yliopiston julkaisuja. Sarja B, Humaniora, oo82-6987; osa 326.

Kääriäinen, Kimmo; Niemelä, Kati \& Ketola, Kimmo (2003). Moderni kirkkokansa: Suomalaisten uskonnollisuus uudella vuosituhannella. Kirkon tutkimuskeskuksen julkaisuja 82, Jyväskylä: Gummerus.

Langøien, Lars Jørun (2012). Yoga, change and embodied enlightenment. Approaching religion 2:2, 27-37.

Lau, Kimberly J. (2000). New age capitalism: Making money east of Eden. Philadelphia: University of Pennsylvania Press.

Lears, Jackson T.J. (1983). From salvation to self-realization: Advertising and the therapeutic roots of the consumer culture, 1880-1930. Teoksessa: Wightman Fox, Richard \& Lears, Jackson T. J. (toim.). The culture of consumption: Critical essays in American history, 1880-1980. New York: Pantheon Books, $1-38$.

Markula, Pirkko (2001). Beyond the perfect body: Women's body image distortion in fitness magazine discourse. Journal of sport Q social issues 25:2, 158-179.

Miles, Matthew B. \& Huberman A. Michael (1994). Qualitative data analysis. Thousand Oaks: Sage.

Nevrin, Klas (2008). Empowerment and using the body in modern postural yoga. Teoksessa: Singleton, Mark \& Byrne, Jean (toim.): Yoga in the modern world: Contemporary perspectives. London ; New York : Routledge, 119-139.

Newcombe, Suzanne (2007). Stretching for health and well-being: Yoga and women in Britain, 19601980. Asian medicine 3:1, 37-63.

Puustinen, Liina (Tulossa 2013). Tehtävä joogalle: Uusliberaalin yhteiskunnan kauniit ja notkeat. Teoksessa: Lehtonen, Mikko.; Kuusela, Hanna. \& Valaskivi, Katja (toim.): Tehtävä kulttuurille. Helsinki: Gaudeamus. 
Philp, John (2009). Yoga, Inc. A journey through the big business of yoga. Canada: Penguin Group.

Putney, Clifford (2001). Muscular Christianity. Manhood and sports in Protestant America, 1880-1920. Cambridge: Harvard University Press.

Rautaniemi, Matti (2010). Henkisyys, hyvinvointi, yksilöllisyys ja sosiaalisuus Helsingin Astanga Joogakoulussa. Uskontotieteen pro gradu -tutkielma. Helsingin Yliopisto.

Samuel, Geoffrey (2008). The origins of yoga and tantra: Indic religions to the thirteenth century. Cambridge: Cambridge University Press.

Singleton, Mark (2010). Yoga body: The origins of modern posture practice. Oxford: Oxford University Press.

Sointu, Eeva \& Woodhead, Linda (2008). Spirituality, gender, and expressive selfhood. Journal for the scientific study of religion 47:2, 259-276.

Suomen kuntoliikuntaliitto (2010). Kansallinen liikuntatutkimus 2009-2010: Aikuisliikunta. SLU:n julkaisusarja 6/2010. http://www.kunto.fi/@Bin/27889o/Liikuntatutkimus_ aikuisliikunta_2009-2010.pdf (luettu 15.3.2013)

Taira, Teemu (2006). Notkea uskonto. Turku: Eetos.

Töyry, Maija; Saarenmaa, Laura \& Särkkä, Nanna (2011). Monitieteisyyden haaste aikakauslehtitutkimuksessa: Kohti konsepti- ja tutkimustietoisuutta. Media Q viestintä 34:3, 23-39.

Wernick, Andrew (1991). Promotional culture: Advertising, ideology and symbolic expression. London, Sage.

Wilson, Christopher P. (1983) The rhetoric of consumption: Mass-market magazines and the demise of the gentle reader, 1880-1920. Teoksessa: Wightman Fox, Richard \& Lears, Jackson T. J. (toim.). The culture of consumption: Critical essays in American history, 1880-1980. New York: Pantheon Books, 39-64.

Wightman Fox, Richard \& Lears, Jackson T. J. (toim.) (1983). The culture of consumption: Critical essays in American history, 1880-1980. New York: Pantheon Books. 